(C) 2014 IEEE. Personal use of this material is permitted. Permission from IEEE must be obtained for all other uses, in any current or future media, including reprinting/republishing this material for advertising or promotional purposes, creating new collective works, for resale or redistribution to servers or lists, or reuse of any copyrighted component of this work in other works. 


\title{
Localized deposition of pure platinum nanostructures
}

\author{
Charlene J. Lobo, C. Elbadawi and M. Toth
}

\begin{abstract}
Localized deposition of pure platinum nanostructures was achieved using a combination of focused electron beam induced processing (FEBID) of an inorganic platinum precursor and low temperature annealing in water vapour. This technique enables fabrication of $\mathrm{Pt}$ nanostructures with high spatial resolution and purity, for applications in nanoelectronics, sensing devices and catalysis.
\end{abstract}

Index Terms-Platinum, Nanostructured Materials, Scanning Electron Microscopy, Fabrication

\section{INTRODUCTION}

Focused electron beam induced deposition (FEBID) is a nanofabrication technique in which electrons are used to dissociate surface-adsorbed precursor molecules into volatile (by-product) and non-volatile (target deposition) components, typically under a constant partial pressure of a precursor gas [1]. This technique enables direct writing of high resolution (sub-nm) three-dimensional nanostructures without requiring the use of lithographic masks and resists.

The main limitation of FEBID has been the typically low purity of fabricated structures, which normally contain $\approx 50$ at. \% $\mathrm{C}$ and are composed of nano-sized metal grains in an amorphous carbon matrix [2]. Due to the high carbon content, EBID deposits behave as granular materials with percolative transport properties. A variety of methods have been used to improve the purity of FEBID deposits, including simultaneous and post-deposition annealing in a variety of gaseous atmospheres [1].

FEBID of $\mathrm{Pt}$ has attracted more attention than any other material. Platinum nanostructures are of particular interest for applications such as nanoelectronics (as nanowires for interconnects and contacts [3], nanodots for non-volatile memory devices), plasmonic antennas [4] and catalysis (in biosensors and fuel cells). In all of these applications, the resolution, surface area and purity of the deposited material are critical. FEBID of platinum has so far been conducted in high vacuum (HV) SEM using the standard metalorganic precursor methylcyclopentadienyl platinum trimethyl $\left(\mathrm{MeCpPtMe}_{3}\right)$ in combination with post-deposition annealing in oxygen or a similar reactive gas [5]. However, thermal or electrical annealing of platinum nanowires fabricated by FEBID using metal organic precursors has been found to result in migration of $\mathrm{Pt}$ out of the nanowires, forming a Ptdepleted graphitic carbon deposit.

C.J.L., C.E. and M.T. are at the University of Technology Sydney (Ph: 9514 1673; e-mail: Charlene.lobo@uts.edu.au).
In this work, we show that extremely high purity platinum can be deposited by FEBID using a carbon-free platinum precursor, Tetrakis(trifluorophosphine)platinum $\left(\mathrm{Pt}\left(\mathrm{PF}_{3}\right)_{4}\right)$.

\section{EXPERIMENTAL RESULTS}

\section{A. Platinum deposition process}

The precursor used for $\mathrm{Pt}$ deposition is Tetrakis(triuorophosphine)platinum, $\quad \mathrm{Pt}\left(\mathrm{PF}_{3}\right)_{4} \quad$ (Strem chemicals), a high vapour pressure liquid at room temperature. Due to the sensitivity of this precursor to air and moisture, it was loaded into a peltier-cooled stainless steel bottle in a dry $\mathrm{N}_{2}$ environment, and sealed using a manual valve. Multiple freeze-pump-thaw cycles were used to remove excess nitrogen and $\mathrm{PF}_{3}$ gas, leaving behind only the platinum precursor.

During FEBID experiments, the precursor gas was flowed into a modified XL30 ESEM with an in-situ environmental reaction cell, previously described in [6]. The reaction cell is isolated from the main SEM chamber using a 200 micron pressure limiting aperture between the cell and the electron column. The differentially pumped reaction cell allows for both greater pressure control and a much larger ratio of precursor gas to residual molecules than is achievable using standard FEBID in HV SEMs.

During FEBID experimentation, the pressure in the reaction cell was kept constant at 0.1 Torr $(13 \mathrm{~Pa})$ using a pressure feedback system; the electron beam current was 10 $\mathrm{nA}$; and the accelerating voltage was $10 \mathrm{kV}$. A defocused electron beam (beam diameter $0.6 \mathrm{~mm}$ ) with a top-hat beam profile was used to dissociate the precursor, forming deposits with diameters of $5 \mu \mathrm{m}$. A set of three 'defocused' deposits was fabricated by FEBID, with deposition times of 30 minutes each (Fig. 1a). Nanodot arrays can also be fabricated using very short beam dwell times (Fig. 1b). The defocused deposits are sufficiently large that the electron beam interaction volume is entirely contained within them, permitting compositional analysis by wavelength or energy dispersive $\mathrm{x}$-ray spectroscopy (WDX or EDX). 


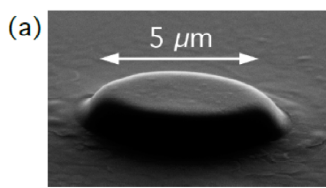

(b)
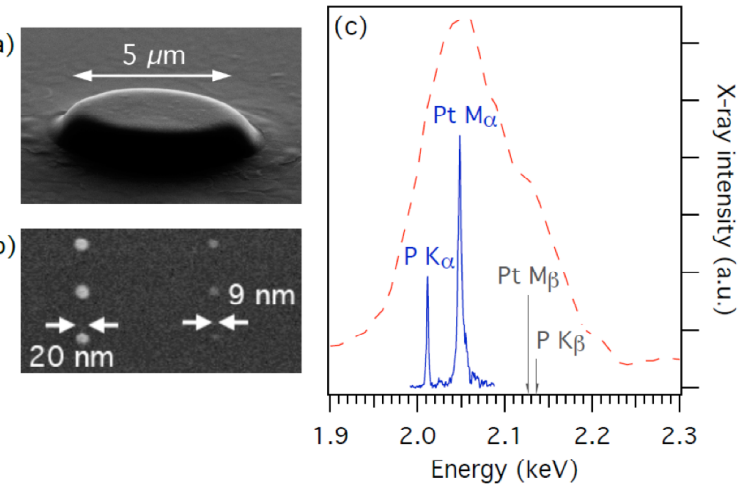

Fig 1. (a) Example of a typical defocused Pt deposit created specifically for compositional analysis. (b) High resolution Pt nano-dots. (c) WDX and EDX spectra of the same deposit region, highlighting the spectral resolution of each technique with regard to the Pt and $\mathrm{P}$ x-ray lines.

\section{B. Compositional analysis}

The composition of as-grown and annealed deposits was analyzed by WDX) (Fig. 2). This technique was chosen due to its' very high spectral resolution $(<10 \mathrm{eV})$, which enables the normally overlapping P K and Pt M X-ray lines to be resolved. Deposits grown at room temperature have a typical atomic composition of $47 \pm 5 \% \mathrm{Pt}, 30 \pm 5 \% \mathrm{P}$ and $15 \pm 10 \%$ O.

\section{Post-deposition annealing}

The trace amounts of fluorine and the presence of oxygen in the as-grown deposits indicate efficient dissociation and desorption of $\mathrm{PF}_{3}$ and $\mathrm{F}$, accompanied by oxidation of $\mathrm{P}$ by residual water present in the vacuum chamber. In order to further purify the material, postdeposition thermal annealing was performed in an ex-situ CVD chamber in a water vapour environment at a pressure of 1 torr (130 $\mathrm{Pa}$ ). Deposits were annealed for 40-60 minutes in vacuum, and in $\mathrm{H}_{2} \mathrm{O}, \mathrm{O}_{2}$ and $\mathrm{NH}_{3}$ environments at a pressure of $130 \mathrm{~Pa}$.

Annealing in vacuum, $\mathrm{O}_{2}$ and $\mathrm{NH}_{3}$ environments had no significant effect on composition. However, low temperature (400$600{ }^{\circ} \mathrm{C}$ ) annealing in water vapour can increase the Pt content to the point where it is indistinguishable from reference, high purity $\mathrm{Pt}$ films by WDS analysis, as shown in Fig. 2. Temperatures of only $400{ }^{\circ} \mathrm{C}$ are required to obtain Pt purity of $94 \%$ after 300 min, with the remaining $5 \%$ being due to $\mathrm{O}$ and $\mathrm{C}$ impurities from adsorbed hydrocarbons and formation of a surface oxide layer during the WDS analysis.

\section{CONCLUSION}

We have reported a new method of fabricating highly pure, nanoscale Pt by combining FEBID with low temperature $\left(<400{ }^{\circ} \mathrm{C}\right)$ post-deposition annealing in water vapour. The low annealing temperature results in little or no nanostructure deformation, which can be a major problem with other FEBID methods for obtaining pure Pt and other materials.

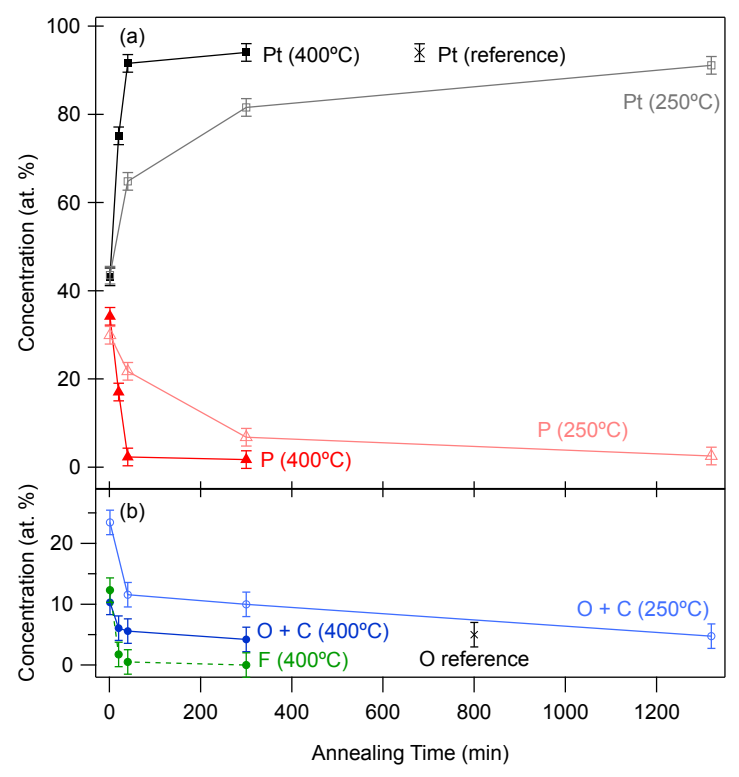

Fig 2. Composition of $\mathrm{Pt}\left(\mathrm{PF}_{3}\right)_{4}$-EBID deposits plotted as a function of annealing time in $\mathrm{H}_{2} \mathrm{O}$ vapor at 250 and $400{ }^{\circ} \mathrm{C}$. Fully purified $\mathrm{Pt}$ deposits are obtained after annealing for $300 \mathrm{~min}$ at $400{ }^{\circ} \mathrm{C}$. The measured composition of a reference, high purity $\mathrm{Pt}$ film is also shown. [Adapted from Ref. 7]

\section{ACKNOWLEDGMENT}

C.E. acknowledges supplemental funding of a UTS APA PhD scholarship from CSIRO Lindfield NSW.

\section{REFERENCES}

[1] I. Utke, S. Moshkalev, S, P. Russell, Nanofabrication Using Focused Ion and Electron Beams: Principles and Applications. New York: Oxford University Press, 2012.

[2] F. Porrati, R. Sachser, C. Schwalb, and M. Huth, "Tuning the electrical conductivity of Pt-containing granular metals by postgrowth electron irradiation," J. Appl. Phys. vol. 107, pp. 206803:1-5, 2011.

[3] V. Gopal et al, "Rapid prototyping of site-specific nanocontacts by electron and ion beam assisted direct-write nanolithography," Nano Lett. vol. 4, pp. 2059-2063, 2004.

[4] K. Hoeflich, R. B. Yang, A. Berger, G. Leuchs, S. Christiansen, "The Direct Writing of Plasmonic Gold Nanostructures by Electron-BeamInduced Deposition," Adv. Mater. vol. 23, pp. 2657-2661, 2011.

[5] A. Botman, J. J. L. Mulders, R. Weemaes. and S. Mentink, "Purification of platinum and gold structures after electron-beaminduced deposition," Nanotechnology vol.17, pp. 3779-3785, 2006.

[6] C. J. Lobo, A. Martin, M. R. Phillips, and M. Toth, "Electron beam induced chemical dry etching and imaging in gaseous $\mathrm{NH}_{3}$ environments", Nanotechnology vol. 23, pp. 375302, 2012.

[7] C. ElBadawi, M. Toth and C. J. Lobo, "Pure Platinum Nanostructures Grown by Electron Beam Induced Deposition," ACS Appl. Mater. Interfaces, vol. 5, pp. 9372-9376 (2013). 
